\title{
Hubungan Jumlah Tenaga Perawat dengan Beban Kerja Perawat Pelaksana di Ruang Rawat Inap Kelas III RSUD Wates
}

\author{
Wahyu Rizky ${ }^{1}$, Nurharyanti Darmaningtyas ${ }^{2}$, Brune Indah Yulitasari ${ }^{3}$, \\ ${ }^{1}$ Administrasi Rumah Sakit, Universitas Alma Ata \\ ${ }^{2}$ IImu Keperawatan, Universitas Alma Ata \\ ${ }^{3}$ Ilmu Keperawatan, Universitas Alma Ata \\ Email: w_rizky30@yahoo.co.id \\ Jalan Brawijaya No.99 Yogyakarta
}

\begin{abstract}
Abstrak
Jumlah perawat di seluruh dunia menurut WHO ada 19,3 juta perawat, sedangkan di Indonesia terdapat 147,264 . Secara nasional, rasio perawat adalah 87,65 per 100.000 penduduk, masih jauh dari target tahun 2019a yaitu 180 per 100.000 penduduk. Hal ini menunjukkan bahwa tenaga perawat masih sangat terbatas, dan keterbatasanA ini bisa menyebabkan beban kerja perawat menjadi tinggi. Tujuan penelitian ini untuk mengidentifikasi dan menganalisa hubungan jumlah tenaga perawat dengan beban kerja perawat pelaksana. metodologi penelitian ini menggunakan deskriptif korelasional dengan rancangan penelitian cross sectional. Teknik pengambilan sampling dengan total sampling. Analisa data bivariat menggunakan uji statistik kendal tau dengan SPSS 22. Hasil penelitian ini dari total 41 responden yang menunjukkan beban kerjanya tinggi sebanyak 32 responden $(78 \%)$ dengan jumlah perawat yang tersedia di bangsal masih kurang dari jumlah ideal menurut perhitungan Depkes. Uji Kendal's Tau menunjukkan nilai $\rho$ value sebesar $0,000<0,05(\alpha: 0,05)$ yang artinya terdapat hubungan antara jumlah tenaga perawat dengan beban kerja perawat pelaksana. Kesimpulan beban kerja paling tinggi terdapat di bangsal dengan jumlah tenaga perawat yang kurang dari jumlah ideal sesuai perhitungan Depkes.
\end{abstract}

Kata kunci: jumlah tenaga perawat, beban kerja, perawat pelaksana

\section{Correlation Between Quantity of Nurse and Workload of Nurses on Duty in Class III at RSUD Wates Hospital}

\section{Abstract}

According to WHO, there are 19.3 million nurses worldwide, and in Indonesia alone, the number of nurses reach 147264. Nationally, nurse ratio is 87.65 per 100000 opulations, far from 2019 target around 180 per 100000 populations. JThis facts show that nurse are still very limited and this limitation cause their workload become heavy. The purpose this study was to identify and analyze correlation of the quantity of nurse with workload of nurses on duty. Methods of this study was correlation descriptive with cross sectional design. Sample collected using total sampling method. Bivariate data analysis done with Kendal's Tau statistical test using SPSS 22. The result showed among 41 total respondents, 32 (78\%) showed their workloads are high and the numbers of nurse on duty are less than the ideal amount recommended by Health Department's calculation. Kendal's Tau test revealed pvalue $0.000<0.05(\alpha: 0.05)$ which means that there is a correlation between quantity of nurses with workload of nurse on duty. Conclusion highest workload found in wards with nurse quantity less than Health Department's recommendation.

Keywords: nurse quantity, workload

Received: 3/1/2018; published: 28/05/2018

\section{PENDAHULUAN}

Rumah sakit merupakan institusi (suatu kesatuan fungsi yang di dalam UUD disebut sebagai fasilitas kesehatan) yang memberikan pelayanan medis sekunder atau rujukan, baik yang sifatnya relative sederhana yaitu perawatan maupun pelayanan medis yang kompleks sering disebut pelayanan tersier seperti bedah jantung dan bedah otak (1).

\section{World Health Organization} (WHO) menyatakan bahwa jumlah perawat di seluruh dunia pada tahun 2011 ada 19,3 juta perawat (2). Sedangkan di Indonesia jumlah perawat di rumah sakit terdapat 147.264 orang perawat $(45,65 \%)$ dari seluruh 
jumlah tenaga kesehatan di rumah sakit. Secara nasional, rasio perawat adalah 87,65 per 100.000 penduduk. Hal ini masih jauh dari target 2019 yaitu 180 per 100.000 penduduk (3). Rasio perawat di Yogyakarta sebanyak 122,74 per 100.000 penduduk, dan di Kulon Progo rasio perawatnya sebanyak 84,91 per 100.000 penduduk, masih jauh dari target yang sebesar 158 per 100.000 penduduk (4).

Penelitian mengenai beban kerja tenaga keperawatan telah.dilakukan di RSU Kota Tangerang Selatan, dimana hasil penelitiannya menunjukkan bahwa beban kerja di instalasi rawat inap Kelas II dan Kelas III di RSU Kota Tangerang Selatan tergolong berat karena beban kerja produktif berada diatas $80 \%$ dan dari hasil perhitungan didapatkan adanya kekurangan tenaga perawat di instalasi rawat inap kelas II dan kelas III sebanyak 9 orang (5). Penelitian lainnya juga dilakukan pada Instalasi Gawat Darurat RSUD Kota Semarang didapatkan gambaran bahwa beban kerja perawat sebagian besar adalah tinggi yaitu sebanyak 27 responden $(93,1 \%)(6)$.

RSUD Wates memiliki kapasitas tempat tidur sebanyak 456 tempat tidur dengan jumlah perawat pelaksana di Ruang Rawat Inap sebanyak 300 orang. Menurut Permenkes Nomor 56 Tahun 2014 bahwa RS Tipe B jumlah kebutuhan tenaga keperawatan sama dengan jumlah tempat tidur pada instalasi rawat inap (7). Jika dilihat dari jumlah yang ada di RSUD Wates, jumlah perawat yang 300 orang belum sama dengan jumlah tempat tidur yang ada sebanyak 456 tempat tidur di ruang rawat inap, jika dibandingkan dengan Peraturan Menteri Kesehatan Nomor 56
Tahun 2014 maka di RSUD Wates ada kekurangan tenaga perawat. Berdasarkan uraian tersebut maka peneliti tertarik untuk meneliti hubungan jumlah tenaga perawat dengan beban kerja perawat pelaksana di Ruang Rawat Inap Kelas III di RSUD Wates.

\section{BAHAN DAN METODE}

Penelitian yang dilakukan merupakan penelitian deskriptif korelatif dengan rancangan penelitian cross sectional. Variabel penelitian ini Variabel bebas (independent) nya yaitu jumlah tenaga perawat dan variabel terikatnya adalah beban kerja perawat pelaksana. Analisa data penelitian ini menggunakan analisa univariat dan analisa bivariat dengan uji kendal's tau karena untuk mencari korelasi antara dua skala data ordinal dan ordinal (7).

\section{HASIL DAN BAHASAN}

Tabel 1 Rekapitulasi Distribusi Frekuensi

Berdasarkan Karakteristik Responden Ruang Rawat Inap Kelas

\begin{tabular}{lll}
\hline $\begin{array}{l}\text { Karakteristik } \\
\text { Responden }\end{array}$ & $(\mathbf{f})$ & (\%) \\
\hline $\begin{array}{l}\text { Jenis Kelamin } \\
\text { Laki-laki }\end{array}$ & 8 & 19,5 \\
Perempuan & 33 & 80,5 \\
\hline Umur & & \\
$21-30$ & 31 & 75,6 \\
$31-40$ & 9 & 22,0 \\
$51-60$ & 1 & 2,4 \\
Jumlah & 41 & 100 \\
\hline
\end{tabular}

Sumber: Data Primer 2017

Berdasarkan Tabel 2 menunjukkan bahwa karakteristik responden di ruang rawat inap kelas III RSUD Wates sebagai berikut: dari 41 responden mayoritas berjenis kelamin 
perempuan sebanyak 33 responden $(80,5 \%)$, dan umur terbanyak responden adalah rentan 21-30 tahun sebanyak 31 orang $(75,6 \%)$ dari total responden. Karakteristik Pendidikan terakhir responden mayoritas berpendidikan D3 sebanyak 39 responden (95,1\%) yang mayoritas lama bekerja nya selama kurun waktu antara 0-5 tahun sebanyak 8 responden(68,3\%).

Hasil penelitian ini sejalan dengan penelitian yang dilakukan oleh Edi Sukoco dengan hasil bahwa sebagian besar responden di Rumah Sakit Umum Pusat dr.Sardjito Yogyakarta berjenis kelamin perempuan yaitu sebanyak 51 responden (68\%) dengan mayoritas responden berada pada usia 20-35 tahun sebanyak 54 responden $(72 \%)$ dan sebagian besar berpendidikan D3 sebanyak 42 responden (72\%) (8). Hal ini menunjukkan bahwa pekerjaan perawat masih banyak diminati oleh perempuan dibandingkan laki-laki. Perawat di RSUD Dr. Tjitrowardoyo Purworejo bekerja selama 1-5 tahun yaitu sebanyak 21 responden (32,3\%) (9). Hal ini sesuai dengan teori bahwa salah satu faktor eksternal yang mempengaruhi beban kerja adalah lama bekerja (10).

\section{Jumlah Tenaga Perawat}

Berdasarkan perhitungan Depkes didapatkan hasil sebagai berikut:

Tabel 2 Jumlah Kebutuhan Tenaga Perawat Menurut Depkes di Ruang Rawat Inap Kelas III RSUD Wates

\begin{tabular}{lccc}
\hline Bangsal & \multicolumn{3}{c}{ Jumlah Tenaga Perawat } \\
\hline & Tersedia & Depkes & Selisih \\
\hline Bougenvil & 15 & 16 & 1 \\
Edelwais & 19 & 21 & 2 \\
Gardenia & 19 & 19 & 0 \\
Jumlah & 53 & 56 & 3 \\
\hline
\end{tabular}

Sumber: Data Primer 2017
Karakteristik responden ini dengan teori bahwa jenis kelamin dan Berdasarkan Tabel 2, hasil penelitian usia merupakan salah satu faktor internal yang mempengaruhi beban kerja (10). Berdasarkan Tabel 2 menunjukkan bahwa untuk karakteristik lama bekerja di Ruang rawat inap kelas III RSUD Wates sebagian besar responden baru bekerja selama 1-5 tahun sebanyak 28 responden (68,3\%). Hasil ini sejalan dengan penelitian Hindun yang menunjukkan bahwa sebagian besar analisis penghitungan rumus Depkes adalah 56 tenaga perawat, dimana bangsal yang kekurangan tenaga paling banyak adalah bangsal 40delweiss sebanyak 2 orang tenaga perawat, untuk bangsal bougenvil membutuhkan tambahan tenaga perawat 2 orang lagi, dan untuk bangsal gardenia jumlah tenaganya sudah tercukupi.

Perhitungan jumlah tenaga perawat pernah dilakukan oleh Syarifuddin Sade di instalasi rawat inap RSUD Mamuju Utara Provinsi Sulawesi Barat tahun 2012 yang menunjukkan bahwa berdasarkan formula PPNI ruang rawat inap RSUD Mamuju Utara masih memerlukan penambahan tenaga perawat sebanyak 13 tenaga perawat (34,21\%) (11). Hal ini menunjukkan bahwa baik RSUD Wates maupun RSUD Mamuju Utara memerlukan penambahan tenaga perawat.

\section{Beban kerja perawat pelaksana}

Tabel 3 Beban kerja perawat

\begin{tabular}{|c|c|c|}
\hline $\begin{array}{l}\text { Beban } \\
\text { Perawat }\end{array}$ & Kerja (f) & (\%) \\
\hline Ringan & 0 & 0 \\
\hline Sedang & 9 & 2 \\
\hline Tinggi & 32 & 8 \\
\hline Jumlah & 41 & 10 \\
\hline
\end{tabular}

Sumber: Data Primer 2017 
Tabel 3 menunjukkan dari 41 responden perawat pelaksana di ruang rawat inap kelas III, 32 orang (78\%) menyatakan bahwa beban kerja mereka adalah tinggi, sedangkan 9 orang (22\%) lainnya menyatakan bahwa beban kerjanya sedang.

Hasil penelitian ini sejalan dengan penelitian yang dilakukan Haryanti di Instalasi Gawat Darurat RSUD Kabupaten Semarang tahun, yang menyebutkan bahwa sebagian besar responden menyatakan beban kerjanya tinggi sebanyak 27 responden $(93,1 \%)$ (6). Hasil penelitian tersebut sesuai dengan teori bahwa beban kerja adalah banyaknya jenis pekerjaan yang harus diselesaikan oleh tenaga kesehatan profesional dalam satu tahun dalam satu sarana pelayanan kesehatan.

\section{Analisa Bivariat}

Tabel 4 Tabulasi Silang dan Uji Kendall's Tau antara Jumlah Tenaga Perawat dengan Beban Kerja Perawat

\begin{tabular}{|c|c|c|c|c|c|c|c|}
\hline \multirow{3}{*}{$\begin{array}{c}\text { Jumlah } \\
\text { Tenaga } \\
\text { Perawat }\end{array}$} & \multicolumn{7}{|c|}{ Beban Kerja Perawat Pelaksanan } \\
\hline & \multicolumn{2}{|c|}{ Sedang } & \multicolumn{2}{|r|}{ Tinggi } & \multicolumn{2}{|c|}{ Total } & \multirow[t]{2}{*}{$\mathbf{P}$} \\
\hline & $\mathbf{n}$ & $\%$ & $\mathbf{n}$ & $\%$ & $\mathbf{n}$ & $\%$ & \\
\hline Kurang & 1 & 2.4 & 25 & 61 & 26 & 63.4 & 0.000 \\
\hline Cukup & 8 & 19.5 & 7 & 17.07 & 15 & 36.6 & \\
\hline Jumlah & 9 & 21.9 & 32 & 78.07 & 41 & 100 & \\
\hline
\end{tabular}

Sumber: Data Primer 2017

Berdasarkan

Tabel

4

menunjukkan bahwa responden yang bekerja di bangsal dengan jumlah perawat yang kurang, 1 orang responden $(2,4)$ menyatakan beban kerjanya sedang, dan 25 responden $(61 \%)$ menyatakan beban kerjanya tinggi. Sedangkan, responden yang bekerja di bangsal dengan tenaga perawat yang cukup menyatakan beban kerja nya sedang sebanyak 8 responden $(19,5 \%)$, dan 7 responden lainnya $(17,07 \%)$ menyatakan beban kerjanya tinggi. Uji korelasi yang digunakan adalah uji Korelasi Kendall's Tau dan didapatkan $\rho$ value sebesar $0,000(\rho<0,005)$ dengan nilai $r=-0,576$. Berdasarkan nilai $\rho$ tersebut dapat disimpulkan bahwa $\mathrm{Ha}$ diterima dan $\mathrm{Ho}$ ditolak, dengan demikian terdapat hubungan antara jumlah tenaga perawat dengan beban kerja perawat pelaksana.

Hasil dari analisis menunjukkan keeratan yang sedang yaitu -,576 dengan arah korelasi negatif yang berarti bahwa apabila jumlah tenaga perawatnya kurang maka beban kerja perawat pelaksananya semakin tinggi. Beban kerja yang tinggi ini dapat meningkatkan terjadinya komunikasi yang buruk antar perawat dengan pasien, kegagalan kolaborasi antara perawat dan dokter, keluarnya perawat dan ketidakpuasan kerja perawat (13).

Hasil penelitian ini sejalan dengan penelitian yang dilakukan oleh Malika yang menyatakan bahwa jumlah tenaga perawat di Instalasi Rawat Inap RSU Kota Tangerang Selatan, berdasarkan hasil perhitungan rumus llyas masih kurang 9 orang perawat dari jumlah tenaga yang tersedia. Kekurangan tenaga perawat ini mengakibatkan beban kerja perawat menjadi berat yaitu $80,36 \%$ di ruang ranap kelas II dan $84,72 \%$ di ruang ranap kelas III (5).

\section{SIMPULAN DAN SARAN}

\section{Simpulan}

Karakteristik responden sebagian besar berjenis kelamin perempuan, dengan rentang umur antara 21-30 tahun, dan berpendidikan D3 dengan lama kerja antara 1-5 tahun. Jumlah tenaga 
perawat di ruang rawat inap kelas III RSUD Wates sebagian besar masih kurang tenaga perawatnya sehingga beban kerja perawat pelaksana di ruang rawat inap kelas III sebagian besa tinggi. Terdapat keeratan hubunga antara jumlah tenaga perawat dengan beban kerja perawat pelaksana.

\section{Saran}

Diharapkan Rumah Sakit mengevaluasi beban kerja perawat untuk mengoptimalkan kinerja perawat pelaksana di RSUD Wates.

\section{DAFTAR PUSTAKA}

1. Kementerian Kesehatan R.I Naskah Akademik Rancangan Undang-Undang Rumah Sakit. 2016;

2. World Health Organization. Global Nursing Number. 2013;

3. Kementerian Kesehatan R.I. Profil Kesehatan Indonesia 2015. Jakarta: Kementerian Kesehatan R.I; 2016.

4. Gunardi. Hubungan Kualitas Pelayanan Perawat dengan Kepuasan Pasien di Poli Bedah RSUD Saras Husada Purworejo. Yogyakarta: Stikes Alma Ata; 2013.

5. Malika R. Analisis Beban Kerja Sebagai Dasar Penentuan Jumlah Kebutuhan Tenaga Perawat di Instalasi Rawat Inap RSU Kota
Tangerang Selatan Pada Tahun 2013. 2013;

6. Aini F, Purwaningsih P. Hubungan Antara Beban Kerja Dengan Stres Kerja Perawat Di Instalasi Gawat Darurat RSUD Kabupaten Semarang. J Manaj Keperawatan. 2013;1(1).

7. Notoatmodjo S. Metodologi penitian kesehatan. Jakarta: Rineka Cipta; 2010.

8. Sukoco E. Hubungan beban kerja perawat dengan kepatuhan dalam pengelolaan sampah medis di instalasi gawat darurat RSUP DR.Sardjito Yogyakarta. 2017;

9. Somadayo H. Hubungan Antara Beban Kerja Perawat dengan Pelaksanaan Komunikasi Terapeutik di Bangsal Penyakit dalam dan Bedah RSUD DR.Tjitrowardoyo Purworejo. 2017; 10.Tarwaka. Ergonomi untuk Keselamatan Kesehatan Kerja dan Produktivitas. Universitas Islam Surakarta: UNIBA Press; 2004.

11. Sade S, Razak A, Thaha R. Kebutuhan Jumlah Tenaga Perawat berdasarkan Beban Kerja pada Instalasi Rawat Inap RSUD Mamuju Utara Provinsi Sulawesi Barat. J Kesehat Masy Unhas. 2012;1(2):88-98. 